\title{
Relationship Between Human Leucocyte Antigen Class I and Class II and Chronic Idiopathic Urticaria Associated With Aspirin and/or NSAIDs Hypersensitivity
}

\author{
Maria Luisa Pacor, ${ }^{1}$ Gabriele Di Lorenzo, ${ }^{2}$ Pasquale Mansueto, ${ }^{2}$ Nicola Martinelli, ${ }^{1}$ \\ Maria Esposito-Pellitteri, ${ }^{2}$ Paola Pradella, ${ }^{3}$ Laura Uxa, ${ }^{3}$ Gaetana Di Fede, ${ }^{4}$ \\ GiovamBattista Rini, ${ }^{2}$ and Roberto Corrocher ${ }^{1}$ \\ ${ }^{1}$ Dipartimento di Medicina Clinica e Sperimentale, Policlinico G.B. Rossi, Università di Verona, Piazzale Scuro, \\ Verona 10-37134, Italy \\ ${ }^{2}$ Dipartimento di Medicina Clinica e delle Patologie Emergenti, Università degli Studi di Palermo, Via del Vespro, \\ Palermo 141-90127, Italy \\ ${ }^{3}$ Servizio Immunotrasfusionale, Ospedale di Cattinara, Azienda Ospedaliero-Universitaria, Ospedali Riuniti di Trieste, \\ Strada di Fiume, Trieste 447- 34149, Italy \\ ${ }^{4}$ Dipartimento di Discipline Chirurgiche ed Oncologiche, Università degli Studi di Palermo, Via L. Giuffrè, \\ Palermo 5 - 90127, Italy
}

Received 3 May 2006; Revised 30 June 2006; Accepted 7 August 2006

Background. HLA genes play a role in the predisposition of several diseases. The aim was to analyze the prevalence of HLA class I phenotypes and HLA-DRB1* genotype in patients with CIU associated with ASA and NSAIDs hypersensitivity (AICU). Methods. 69 patients with AICU, and 200 healthy subjects. Results. Subjects with HLA-B44 and HLA-Cw5 antigens were more represented in patients with AICU than in control group. Subjects with HLA-A11, HLA-B13, HLACw4, and HLA-Cw7 antigen were more represented in control group than in patients with AICU. Multiple logistic regression demonstrated an association of HLA-Cw4 and HLA-Cw7 with a lower risk of AICU, whereas carriers of HLA-B44 phenotype had a higher risk of AICU. No differences were found between patients and controls as regards to HLA-DRB1* genotype. Conclusions. We observed an association between some HLA class-I antigens and AICU. To the best of our knowledge this is the first description of such association.

Copyright ( $) 2006$ Maria Luisa Pacor et al. This is an open access article distributed under the Creative Commons Attribution License, which permits unrestricted use, distribution, and reproduction in any medium, provided the original work is properly cited.

\section{INTRODUCTION}

Urticaria is a common skin disorder characterized by erythematous, raised skin lesions, usually intensely itching, lasting less than 24 hours, or occasionally even longer. By definition, urticaria of $<6$ weeks duration is arbitrarily considered "acute," whereas urticaria recurring $>6$ weeks is referred to as "chronic." Generally, 40 to $60 \%$ of the patients with chronic urticaria do not have a well-described cause ("ordinary" chronic idiopathic urticaria) $[1,2]$.

In approximately $60 \%$ of patients with chronic urticaria it has been demonstrated that intradermal injection of autologous serum causes a weal and flare response typical of an urticarial lesion, due to the presence of $\operatorname{IgG}$ antibodies directed to the $\alpha$ subunit of the high affinity IgE receptor $(\mathrm{Fc} \cong \varepsilon \mathrm{RI})$ on mast cell and basophils (autoreactive chronic urticaria). In other patients, aspirin and/or nonsteroidal anti-inflammatory drugs (NSAIDs) and/or food additives hypersensitivity can aggravate urticaria. However, in many patients the mechanisms causing their urticaria remain obscure [3-5].

The human leucocyte antigen (HLA) genes play a major role in regulating the immune response. HLA class-I and class-II molecules are membrane-bound glycoproteins that bind intracellularly processed antigenic peptides and present them to $\mathrm{T}$ cells via $\mathrm{T}$-cell receptors and are encoded by the most highly polymorphic gene family in the human genome [6]. HLA class-I molecules are present on all nucleated cells and platelets and present peptides of endogenous origin to CD8+ T cells, while HLA class-II molecules are expressed on a more restricted range of cell types-including B cells, activated $\mathrm{T}$ cells, and the monocyte/macrophage lineage-and 
present short peptides of exogenous origin to CD4+ T cells, mainly with helper phenotype. Therefore, polymorphisms of the HLA molecules can modulate the capacity to bound and present different peptides [7].

HLA loci play a well-known role in predisposition to several and different diseases, including rheumatoid arthritis, ankylosing spondylitis, coeliac disease, insulin-dependent diabetes mellitus, multiple sclerosis, atopic disease, and food allergy [8]. Mainly HLA type-II polymorphisms have been associated with such diseases, but also the HLA type-I locus has been found in relation with some pathologies (ie, HLAB27 and ankylosing spondylitis) [9].

The aim of our study is to analyze the prevalence of HLA class-I phenotypes (HLA A, B, Cw) and HLA-DRB1* genotype in blood from patients affected by chronic idiopathic urticaria associated with aspirin and/or NSAIDs hypersensitivity (AICU).

\section{MATERIALS AND METHODS}

\section{Patients}

A total of 69 patients ( 16 males, 53 females; mean age $42.3 \pm$ 16.2 years), affected by AICU, living in North-East Italy, were selected from the outpatient clinic of the Dipartimento di Medicina Clinica, Università di Verona (Italy). AICU was defined as the presence of urticarial lesions recurring $>6$ weeks, exacerbated by the administration of aspirin and/or NSAIDs, without any other known secondary causes. In all patients we performed a specific challenge with oral acetylsalicylic acid (ASA) (see below). The presence of urticarial skin lesions, with or without angioedema, was clinically confirmed in all patients. Our institutional policy and the ethical committee in our institution do not require that an ethics committee authorize the study. However, institutional policy requires the patient's written informed consent for us to perform the study; we obtained consent in every case. The study was carried out during the period between January 2002 and December 2003.

Patients with physical urticaria, positive skin test to autologous serum, or food additives hypersensitivity were excluded from the study [10-13]. The control group was represented by 200 healthy subjects, enrolled in the bone marrow donors register (97 males, 103 females; mean age $29.9 \pm$ 4.9 years), from the same geographic region, sex- and agematched. No subject of the control group was affected by atopic/allergic diseases and/or acute or chronic urticaria.

\section{Oral acetylsalicylic acid challenge}

All patients performed a double-blind, placebo-controlled challenge (DBPC) with ASA. For the DBPC we used ASA and placebo. They were in gelatin capsule (LoFarma, Milan, Italy). None of the patients presented urticaria symptoms at the time of testing. Antihistamines had been interrupted 3 days before the challenges. An informed consent was obtained from all the subjects. Challenges were administered using a double-blind placebo-controlled procedure during the morning hours. Before DBPC, patients received a sham- challenge with placebo (talc). When no urticaria symptoms were noted after placebo, 1 hour later, DBPC was performed using ASA and placebo. They were given in a randomized sequence: three placebo capsules and three doses of ASA (10 mg, $10 \mathrm{mg}$, and finally $20 \mathrm{mg}$ ). Each dose was given after 1 hour, if no symptoms had developed with the previous administration. Only the appearance of unequivocal worsening of urticaria (defined as pruritic and erythematous areas raised over normal skin) and/or the appearance of angioedema (defined as swelling of the skin and/or external mucosa) were considered as a positive response [11-13].

\section{HLA class-I phenotype and HLA-DRB1* genotype}

HLA class-I antigens were typed by serology with human antisera using the standard complement-dependent microlymphocytotoxicity assay, using a panel of 100 lymphocytes. The antisera used for typing locus A were 1, 2, 3, 9, 10, 11, 23, 24, $25,26,28,29,30,31,32,33,34,35,37,40,43,66,68,69,74$; for typing locus B 5, 7, 8, 12, 13, 14, 15, 16, 17, 18, 21, 22, 23, $27,37,38,39,40,41,42,44,45,46,47,49,50,51,52,53,54$, $55,56,57,58,60,61,62,63,64,65,70,71,72,73,75,76,77$; for typing locus $\mathrm{Cw} 1,2,3,4,5,6,7,8,17$.

DNA was prepared from ethylenediamine tetraacetic acid-anticoagulated blood. A salting-out method was used to extract genomic DNA, which was then precipitated, washed with ethanol, and resuspended in water. Then, for each sample, HLA class-II genotyping was performed for HLADRB1 ${ }^{*}$, evaluating the $1,3,4,7,8,9,10,11,12,13,14,15,16$, and 17 alleles, by using a "low-resolution" polymerase chain reaction amplification with sequence-specific primers (PCRSSP) (Olerup Low-Resolution Kit).

\section{Statistical methods}

Data were analyzed with SPSS 13.0 statistical package (SPSS Inc, Chicago, Ill). Quantitative data were assessed with Student $t$ test. Associations between qualitative variables, such as prevalence of HLA phenotypes and genotype, in patients and control groups, were analyzed with $\chi 2$-test or Fisher-exact test when indicated. Statistical significance was set at $P$ values smaller than .05. To better evaluate the potential association between HLA phenotypes and genotype and AICU, we also performed a multiple logistic regression analysis, including all the HLA phenotypes and genotype with a significant different distribution in the univariate analysis. To assess the strength of these associations, odds ratios (OR), with 95\% confidence interval (95\% CI), were calculated.

\section{RESULTS}

The frequency of HLA class-I phenotypes and HLA-DRB1* alleles in patients with AICU and in the control group is shown in Tables $1(\mathrm{a})-1(\mathrm{~b})$.

In our population, 6 HLA class-I antigens presented a significantly different distribution between patients and controls; whereas no significant difference was found for the HLADRB1* alleles distribution. Subjects with HLA-B44 
TABLE 1: (a)-(d): HLA class-I (A, B, and Cw) phenotypes and HLADRB1* genotypes in patients affected by AICU and in the control group.

\begin{tabular}{lccc}
\hline & $\begin{array}{c}\text { Control group } \\
(n=200)\end{array}$ & $\begin{array}{c}\text { CIU AICU group } \\
(n=69)\end{array}$ & $P$ \\
\hline $\begin{array}{l}\text { HLA-A } \\
\text { (phenotype carrier) }\end{array}$ & & & \\
\hline 1 & $21.0 \%$ & $23.2 \%$ & NS* \\
2 & $48.5 \%$ & $52.2 \%$ & NS \\
3 & $18.5 \%$ & $24.6 \%$ & NS \\
9 & $0 \%$ & $0 \%$ & NS \\
10 & $0.5 \%$ & $0 \%$ & NS \\
11 & $13.0 \%$ & $4.3 \%$ & $\mathbf{. 0 4 6}$ \\
23 & $6.0 \%$ & $2.9 \%$ & NS \\
24 & $32.5 \%$ & $26.1 \%$ & NS \\
25 & $2.5 \%$ & $7.2 \%$ & NS \\
26 & $8.0 \%$ & $5.8 \%$ & NS \\
28 & $0.5 \%$ & $4.3 \%$ & NS \\
29 & $2.0 \%$ & $2.9 \%$ & NS \\
30 & $7.5 \%$ & $2.9 \%$ & NS \\
31 & $6.5 \%$ & $2.9 \%$ & NS \\
32 & $8.0 \%$ & $5.8 \%$ & NS \\
33 & $4.5 \%$ & $5.8 \%$ & NS \\
34 & $0 \%$ & $0 \%$ & NS \\
35 & $0 \%$ & $0 \%$ & NS \\
37 & $0 \%$ & $0 \%$ & NS \\
40 & $0 \%$ & $0 \%$ & NS \\
43 & $0 \%$ & $0 \%$ & NS \\
66 & $0.5 \%$ & $0 \%$ & NS \\
68 & $9.5 \%$ & $11.6 \%$ & NS \\
69 & $0 \% \%$ & NS \\
74 & $0 \%$ & $0 \%$ & NS \\
\hline & & &
\end{tabular}

(a)

\begin{tabular}{lccc}
\hline $\begin{array}{l}\text { HLA-B } \\
\text { (phenotype carrier) }\end{array}$ & $\begin{array}{c}\text { Control group } \\
(n=200)\end{array}$ & $\begin{array}{c}\text { CIU AICU } \\
\text { group }(n=69)\end{array}$ & $P$ \\
\hline 5 & $0 \%$ & $0 \%$ & NS \\
7 & $13.5 \%$ & $11.6 \%$ & NS \\
8 & $13.5 \%$ & $5.8 \%$ & NS \\
12 & $0 \%$ & $0 \%$ & NS \\
$\mathbf{1 3}$ & $\mathbf{9 . 5} \%$ & $\mathbf{0} \%$ & $\mathbf{. 0 0 5}$ \\
14 & $1.5 \%$ & $0 \%$ & NS \\
15 & $2.0 \%$ & $0 \%$ & NS \\
16 & $0.5 \%$ & $0 \%$ & NS \\
17 & $2.0 \%$ & $1.4 \%$ & NS \\
18 & $17.0 \%$ & $23.2 \%$ & NS \\
21 & $0 \%$ & $0 \%$ & NS \\
22 & $0 \%$ & $0 \%$ & NS \\
23 & $0 \%$ & $1.4 \%$ & NS \\
27 & $6.0 \%$ & $7.2 \%$ & NS \\
35 & $29.0 \%$ & $24.6 \%$ & NS \\
37 & $3.0 \%$ & $4.3 \%$ & NS \\
38 & $4.5 \%$ & $4.3 \%$ & NS \\
39 & $8.0 \%$ & $4.3 \%$ & NS \\
40 & $2.5 \%$ & $0 \%$ & NS \\
41 & $0.5 \%$ & $4.3 \%$ & NS \\
42 & $0 \%$ & $0 \%$ & NS \\
44 & $\mathbf{1 3 . 0 \%}$ & $\mathbf{2 9 . 0 \%}$ & $\mathbf{0 . 0 0 2}$ \\
45 & $1.0 \%$ & $1.4 \%$ & NS \\
\hline & & &
\end{tabular}

\begin{tabular}{lccc}
\hline $\begin{array}{l}\text { HLA-B } \\
\text { (phenotype carrier })\end{array}$ & $\begin{array}{c}\text { Control group } \\
(n=200)\end{array}$ & $\begin{array}{c}\text { CIU AICU } \\
\text { group }(n=69)\end{array}$ & $P$ \\
\hline 46 & $0 \%$ & $0 \%$ & NS \\
47 & $1.0 \%$ & $1.4 \%$ & NS \\
49 & $7.5 \%$ & $7.2 \%$ & NS \\
50 & $6.0 \%$ & $1.4 \%$ & NS \\
51 & $20.5 \%$ & $23.2 \%$ & NS \\
52 & $1.0 \%$ & $0 \%$ & NS \\
53 & $2.0 \%$ & $2.9 \%$ & NS \\
54 & $0 \%$ & $0 \%$ & NS \\
55 & $4.0 \%$ & $2.9 \%$ & NS \\
56 & $1.0 \%$ & $1.4 \%$ & NS \\
57 & $8.5 \%$ & $2.9 \%$ & NS \\
58 & $3.0 \%$ & $4.3 \%$ & NS \\
60 & $3.5 \%$ & $2.9 \%$ & NS \\
61 & $0.5 \%$ & $0 \%$ & NS \\
62 & $6.0 \%$ & $8.7 \%$ & NS \\
63 & $1.0 \%$ & $1.4 \%$ & NS \\
64 & $0 \%$ & $0 \%$ & NS \\
65 & $1.5 \%$ & $4.3 \%$ & NS \\
70 & $0 \%$ & $0 \%$ & NS \\
71 & $0 \%$ & $0 \%$ & NS \\
72 & $0 \%$ & $0 \%$ & NS \\
73 & $0.5 \%$ & $0 \%$ & NS \\
75 & $0.5 \%$ & $0 \%$ & NS \\
76 & $0 \%$ & $0 \%$ & NS \\
77 & $0 \%$ & $0 \%$ & NS \\
\hline & $0 \%$ & &
\end{tabular}

(b) Continued.

\begin{tabular}{lccc}
\hline $\begin{array}{l}\text { HLA-Cw } \\
\text { (phenotype carrier) }\end{array}$ & $\begin{array}{c}\text { Control group } \\
(n=200)\end{array}$ & $\begin{array}{c}\text { CIU AICU group } \\
(n=69)\end{array}$ & $P$ \\
\hline 1 & $9.0 \%$ & $5.8 \%$ & NS \\
2 & $8.5 \%$ & $11.6 \%$ & NS \\
3 & $16.0 \%$ & $8.7 \%$ & NS \\
$\mathbf{4}$ & $\mathbf{3 7 . 0 \%}$ & $\mathbf{1 4 . 5} \%$ & $\mathbf{. 0 0 1}$ \\
$\mathbf{5}$ & $\mathbf{5 . 5 \%}$ & $\mathbf{1 4 . 5 \%}$ & $\mathbf{. 0 1 6}$ \\
6 & $17.5 \%$ & $8.7 \%$ & $\mathrm{NS}$ \\
7 & $\mathbf{4 8 . 5 \%}$ & $\mathbf{2 3 . 2 \%}$ & $<.001$ \\
8 & $0 \%$ & $1.4 \%$ & $\mathrm{NS}$ \\
17 & $1.0 \%$ & $0 \%$ & $\mathrm{NS}$ \\
\hline
\end{tabular}

(c)

\begin{tabular}{cccc}
\hline $\begin{array}{l}\text { HLA-DRB1 } \\
\text { (allele carrier })\end{array}$ & $\begin{array}{c}\text { Control group } \\
(n=200)\end{array}$ & $\begin{array}{c}\text { CIU AICU group } \\
(n=69)\end{array}$ & $P$ \\
\hline 1 & $16.0 \%$ & $15.9 \%$ & NS \\
3 & $21.0 \%$ & $14.5 \%$ & NS \\
4 & $15.5 \%$ & $10.1 \%$ & NS \\
7 & $24.0 \%$ & $26.1 \%$ & NS \\
8 & $7.5 \%$ & $4.3 \%$ & NS \\
9 & $1.0 \%$ & $0 \%$ & NS \\
10 & $3.5 \%$ & $0 \%$ & NS \\
11 & $39.5 \%$ & $44.9 \%$ & NS \\
12 & $6.5 \%$ & $4.3 \%$ & NS \\
13 & $22.0 \%$ & $26.1 \%$ & NS \\
14 & $7.5 \%$ & $11.6 \%$ & NS \\
15 & $15.5 \%$ & $8.7 \%$ & NS \\
16 & $12.0 \%$ & $8.7 \%$ & NS \\
17 & $1.0 \%$ & $0 \%$ & NS \\
\hline
\end{tabular}

* By $\chi^{2}$ test or Fisher's exact test; NS: not significant. 
antigen were more represented in patients affected by AICU than in control group (29\% versus $13 \% ; P=.002)$, as well as subjects with HLA-Cw5 antigen (14.5\% versus 5.5\%; $P=.016)$. On the other hand, subjects with HLA-A11 $(4.3 \%$ versus $13 \% ; P=.046)$, HLA-B13 (0\% versus $9.5 \% ; P=$ $.005)$, HLA-Cw4 (14.5\% versus $37 \% ; P=.001)$, and HLACw7 antigen $(23.2 \%$ versus $48.5 \%$; $P<.001)$ were more represented in control group than in patients affected by AICU. Then we performed a multiple-logistic regression, including all the above-mentioned HLA antigens; only three HLA phenotypes maintained a significant different distribution, more precisely, HLA-Cw4 (OR 0.18 with 95\% CI 0.08-0.40; $P<.001$ ) and HLA-Cw7 (OR 0.21 with 95\% CI 0.11-0.42; $P<.001)$ remained associated with a lower risk of AICU, whereas carriers of HLA-B44 phenotype had a higher risk of AICU (OR 2.63 with 95\% CI 1.13-6.12; $P=.024$ ).

\section{DISCUSSION}

In this study we demonstrated an association between some HLA class-I antigens and chronic idiopathic urticaria associated with aspirin and/or NSAIDs hypersensitivity (AICU). In particular, two HLA-Cw phenotypes, HLA-Cw4 and HLACw7, seem to be less frequent in patients with AICU, whereas HLA-B44 shows a positive association with this subtype of chronic urticaria. To the best of our knowledge, this is the first description of such association.

Many studies have investigated the etiology of chronic urticaria. Recent researches have focused primarily on the demonstration of IgG antibodies directed to the $\alpha$ subunit of the high affinity IgE receptor (FcERI) on mast cell and basophils, revealed by autologous serum skin test, and on the copresence of aspirin and/or NSAIDs and/or food additives hypersensitivity aggravating urticaria. However, in many patients, the exact mechanisms governing regional mast cell or basophil activation are unknown; this condition is usually indicated by the term of "ordinary chronic idiopathic urticaria" $[1,2]$.

Besides, many questions still remain to be answered, such as the triggering of the autoreactive process, other immunological or not immunological pathogenetic mechanisms, temporary spontaneous remissions, and genetic heterogeneity of the patients [3-5].

gKim et al suggested that some HLA class-II genotypes are a strong genetic marker to determine the aspirin-induced urticaria phenotype [14]. However, the data have not been confirmed by other studies $[15,16]$. The HLA class-I loci, at this time, are relatively less investigated than HLA class-II loci in reference to disease predisposition. Therefore, HLA class-I antigen plays a major role in ankylosing spondylitis [9]. Nevertheless, it is interesting to emphasize that some HLA classI alleles have been reported to be associated with adverse events in patients taking various drugs: HLA-A29 and B12 with Stevens-Johnson syndrome induced by sulphonamide, HLA-A2 and B12 with Stevens-Johnson syndrome induced by NSAIDs $[17,18]$. Recently, the HLA-B*5801 allele has been proposed as a genetic marker for severe cutaneous adverse reactions caused by allopurinol [19].
Furthermore and interestingly, new functions, that could play a role in pathogenetic processes, have been identified for HLA class-I molecules, mainly for HLA-Cw, such as the inhibition of the lytic capacity of natural killer cells and non$\mathrm{MHC}$ restricted $\mathrm{T}$ cells [20].

It is now tempting to speculate that some of HLA classI molecules could be involved in some of the heterogeneous pathogenetic mechanisms of AICU and, consequently, that HLA variants could induce this subtype of chronic urticaria.

In conclusion, we assume that HLA alleles may be involved in the development of AICU as possible predisposing factors.

\section{ABBREVIATIONS}

$$
\begin{array}{ll}
\text { HLA } & \text { human leucocyte antigen } \\
\text { NSAIDs } & \begin{array}{l}
\text { nonsteroidal anti-inflammatory drugs } \\
\text { chronic idiopathic urticaria associated with } \\
\text { aspirin and/or NSAIDs hypersensitivity }
\end{array}
\end{array}
$$

\section{ACKNOWLEDGMENT}

This study was supported by grants from Ministero Italiano Università e Ricerca (MIUR) (fondi ex 60\%) to Gabriele Di Lorenzo, Maria Luisa Pacor, and Pasquale Mansueto, and received no support from the pharmaceutical industry.

\section{REFERENCES}

[1] Greaves MW. Urticaria. Clinical Allergy and Immunology. 2002;16:381-400.

[2] Grattan CE. The urticaria spectrum: recognition of clinical patterns can help management. Clinical and Experimental Dermatology. 2004;29(3):217-221.

[3] Grattan CE, Sabroe RA, Greaves MW. Chronic urticaria. Journal of the American Academy of Dermatology. 2002;46(5):645657.

[4] Kaplan AP. Chronic urticaria: pathogenesis and treatment. Journal of Allergy and Clinical Immunology. 2004;114(3):465474.

[5] Di Lorenzo G, Pacor ML, Mansueto P, et al. Food-additiveinduced urticaria: a survey of 838 patients with recurrent chronic idiopathic urticaria. International Archives of Allergy and Immunology. 2005;138(3):235-242.

[6] Bodmer JG, Marsh SG, Albert ED, et al. Nomenclature for factors of the HLA system, 1996. Human Immunology. 1997; 53(1):98-128.

[7] Rammensee HG, Friede T, Stevanovic S. MHC ligands and peptide motifs: first listing. Immunogenetics. 1995;41(4):178228.

[8] Heard R. HLA and autoimmune disease. In: Lechler R, ed. HLA and Disease. London, UK: Academic Press; 1994:123151.

[9] Nuki G. Ankylosing spondylitis, HLA B27, and beyond. Lancet. 1998;351(9105):767-769.

[10] Di Lorenzo G, Pacor ML, Mansueto P, et al. Randomized placebo-controlled trial comparing desloratadine and montelukast in monotherapy and desloratadine plus montelukast in combined therapy for chronic idiopathic urticaria. Journal of Allergy and Clinical Immunology. 2004;114(3):619-625. 
[11] Di Lorenzo G, Pacor ML, Vignola AM, et al. Urinary metabolites of histamine and leukotrienes before and after placebocontrolled challenge with ASA and food additives in chronic urticaria patients. Allergy. 2002;57(12):1180-1186.

[12] Pacor ML, Di Lorenzo G, Biasi D, Barbagallo M, Corrocher R. Safety of rofecoxib in subjects with a history of adverse cutaneous reactions to aspirin and/or non-steroidal anti-in flammatory drugs. Clinical and Experimental Allergy. 2002; 32(3):397-400.

[13] Pacor ML, Di Lorenzo G, Corrocher R. Efficacy of leukotriene receptor antagonist in chronic urticaria. A double-blind, placebo-controlled comparison of treatment with montelukast and cetirizine in patients with chronic urticaria with intolerance to food additive and/or acetylsalicylic acid. Clinical and Experimental Allergy. 2001;31(10):1607-1614.

[14] Kim SH, Choi JH, Lee KW, et al. The human leucocyte antigen-DRB1 ${ }^{*}$ 1302-DQB1 ${ }^{*}$ 0609-DPB1 ${ }^{*} 0201$ haplotype may be a strong genetic marker for aspirin-induced urticaria. Clinical and Experimental Allergy. 2005;35(3):339-344.

[15] O’Donnell BF, O’Neill CM, Francis DM, et al. Human leucocyte antigen class II associations in chronic idiopathic urticaria. British Journal of Dermatology. 1999;140(5):853-858.

[16] Oztas P, Onder M, Gonen S, Oztas MO, Soylemezoglu O. Is there any relationship between human leucocyte antigen class II and chronic urticaria? (chronic urticaria and HLA class II). Yonsei Medical Journal. 2004;45(3):392-395.

[17] Roujeau JC, Huynh TN, Bracq C, Guillaume JC, Revuz J, Touraine R. Genetic susceptibility to toxic epidermal necrolysis. Archives of Dermatology. 1987;123(9):1171-1173.

[18] Roujeau JC, Bracq C, Huyn NT, Chaussalet E, Raffin C, Duedari N. HLA phenotypes and bullous cutaneous reactions to drugs. Tissue Antigens. 1986;28(4):251-254.

[19] Hung S-I, Chung W-H, Liou L-B, et al. HLA-B* 5801 allele as a genetic marker for severe cutaneous adverse reactions caused by allopurinol. Proceedings of the National Academy of Sciences of the United States of America. 2005;102(11):4134-4139.

[20] Falk CS, Schendel DJ. HLA-C revisited. Ten years of change. Immunologic Research. 1997;16(2):203-214. 


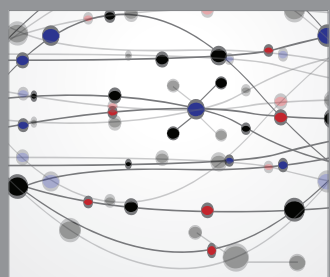

The Scientific World Journal
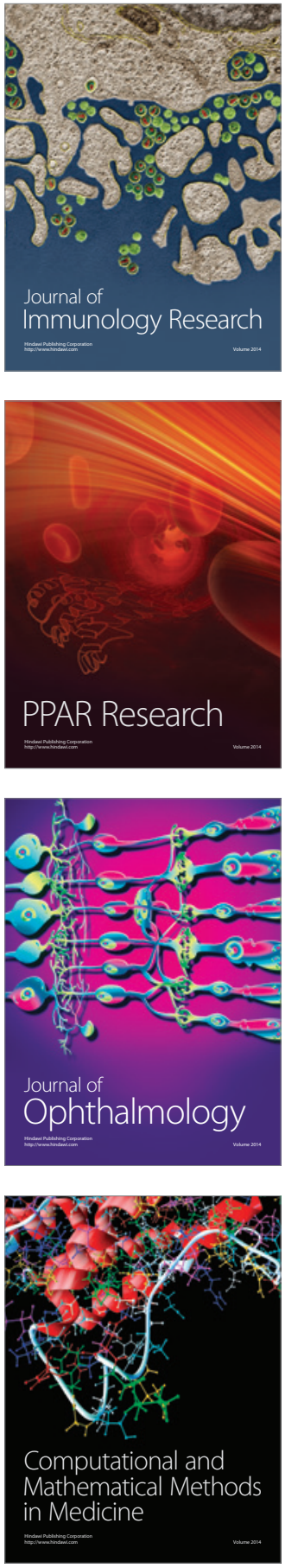

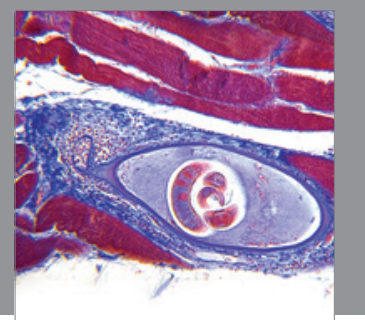

Gastroenterology

Research and Practice
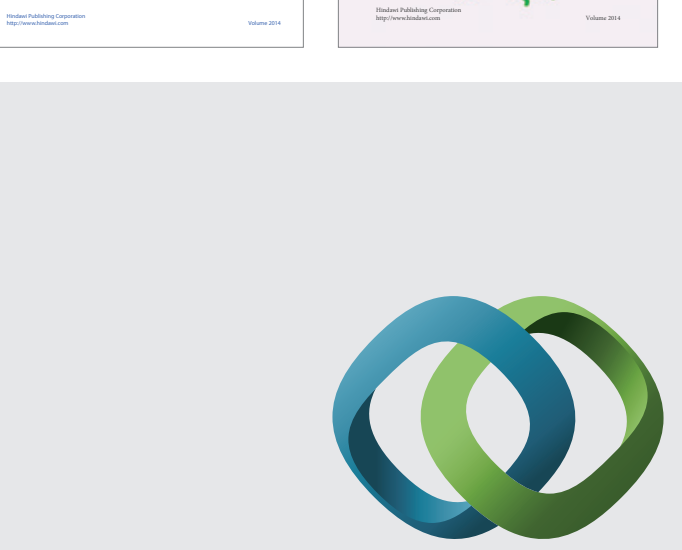

\section{Hindawi}

Submit your manuscripts at

http://www.hindawi.com
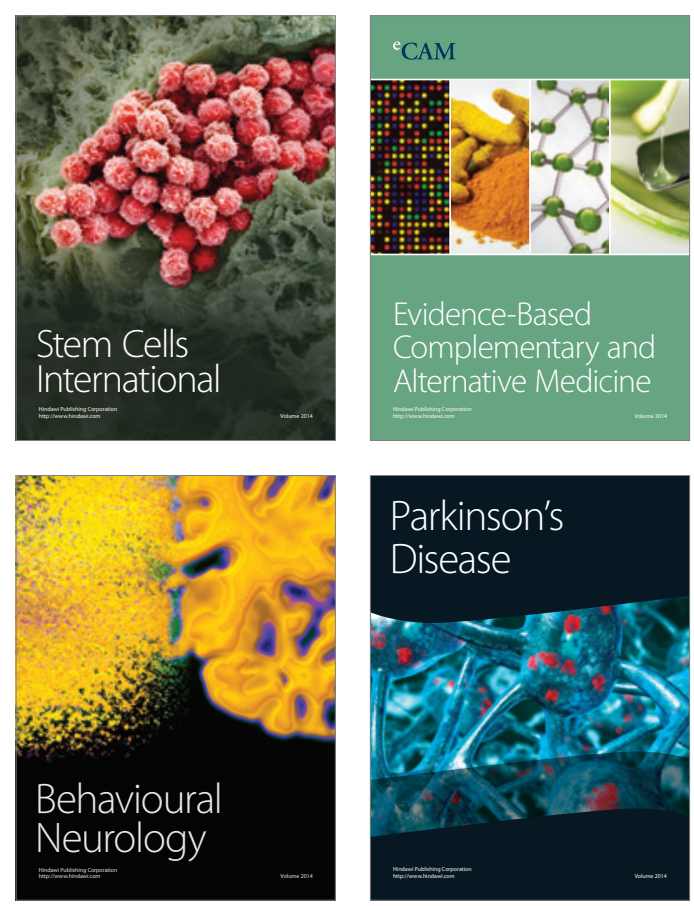

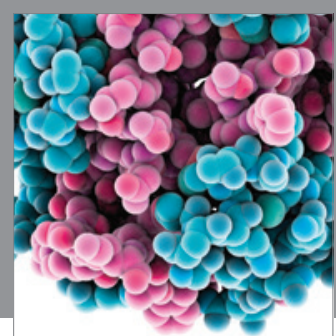

Journal of
Diabetes Research

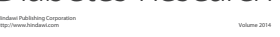

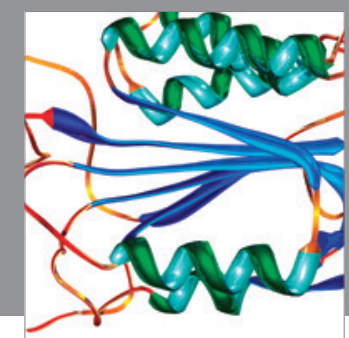

Disease Markers
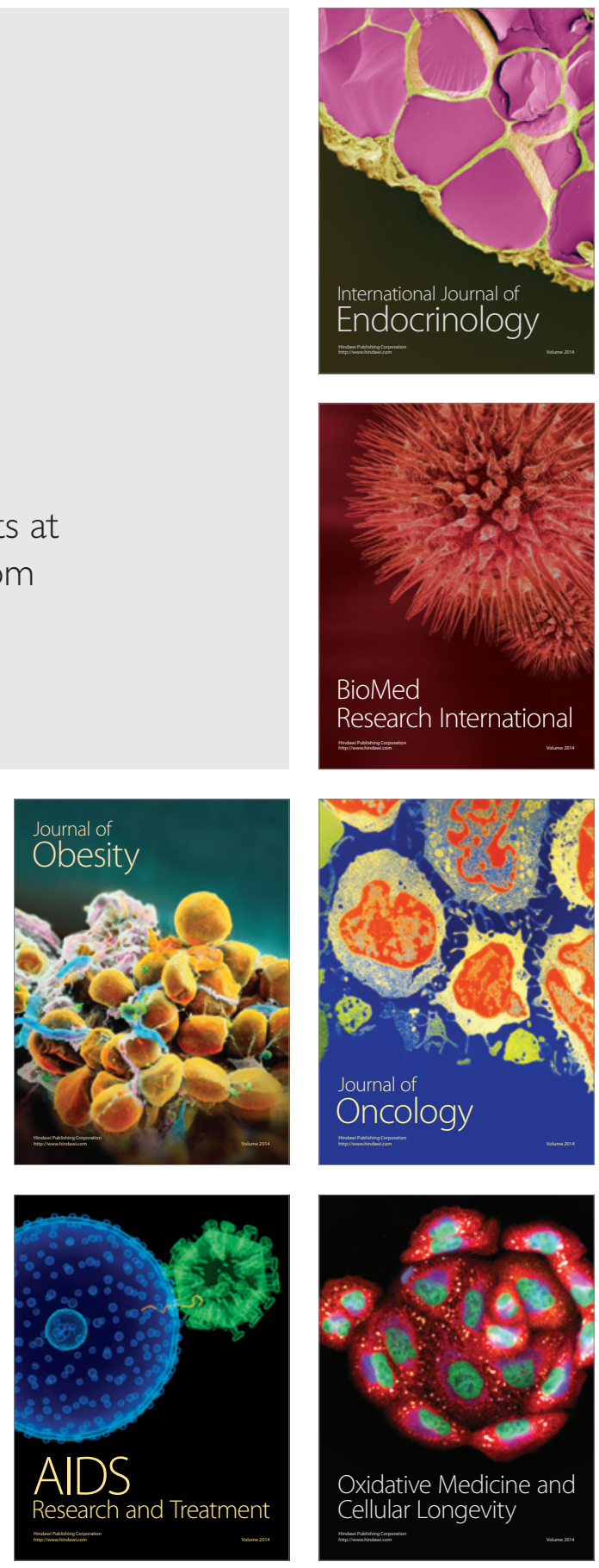